Article

\title{
Prevalence of Overweight and Obesity in a Primary Healthcare Center in Goiania City
}

\author{
Carlos Alexandre Vieira *, Paulo Gentil ${ }^{\mathbb{D}}$, Mário Hebling Campos ${ }^{\mathbb{D} \text {, }}$ \\ Wanderson Divino Nilo dos Santos (iD), Gustavo de Conti Teixeira Costa (iD, \\ Claudio André Barbosa de Lira ${ }^{(D)}$, Elen Cristine Gomes Prado and Tadeu João Ribeiro Baptista \\ College of Physical Education and Dance, Federal University of Goias-UFG, 74690-900 Goiania, Brazil; \\ paulogentil@hotmail.com (P.G.); mariohcampos@gmail.com (M.H.C.); wanderson.nilo@gmail.com (W.D.N.d.S.); \\ conti02@hotmail.com (G.d.C.T.C.); andre.claudio@gmail.com (C.A.B.d.L.); elencristine88@gmail.com (E.C.G.P.); \\ tadeujrbaptista@yahoo.com.br (T.J.R.B.) \\ * Correspondence: vieiraca1@uol.com.br; Tel./Fax: +55-062-3521-1141
}

Received: 19 March 2018; Accepted: 3 May 2018; Published: 8 May 2018

\begin{abstract}
Background: The aim of the present study was to determine the prevalence of overweight and obesity in volunteers supported by a primary healthcare center in Goiania city. Methods: The prevalence of overweight and obesity was calculated using data from a public primary healthcare center in the city of Goiania, Brazil, which serves approximately 10,000 patients. Data were collected between September and October 2011 from individuals aged 20 years or older via medical records. Seven hundred and eighty-nine patients participated in the present study, 546 women $(43.9 \pm 16.4$ years, $66.2 \pm 13.3 \mathrm{~kg}$, $1.6 \pm 0.1 \mathrm{~m})$ and 243 men $(46.0 \pm 17.2$ years, $73.7 \pm 14.7 \mathrm{~kg}, 1.7 \pm 0.1 \mathrm{~m})$. RESULTS: The analysis of variance indicated no significant difference in BMI distribution between genders ( $p=0.0763)$, however, there was a significant difference between age groups $(p=0.0000)$ and a significant association between gender and age $(p=0.0196)$. The percentage of overweight and obesity was above $40 \%$ and the percentage of obese was $15 \%$ in the population studied. The results show a high prevalence of overweight and obesity among adults, especially the elderly. Conclusions: There is a high prevalence of overweight and obesity among adults and the elderly, with a significant difference between age groups and an increase in BMI with age.
\end{abstract}

Keywords: overweight; obesity; public health; unified health system

\section{Introduction}

Both overweight and obesity are continuously increasing worldwide, and in the United States and Brazil have reached levels higher than $16 \%$ of the population [1]. The prevalence of obesity in the United States in 1991 was roughly 12\% and by 2001 had increased to $20.9 \%$ of the population, which represents an augmentation of 74\% [2]. In addition, the prevalence of overweight also increased from $45 \%$ to 58\% between 1991 and 2001 [2]. Ogden et al. [3] highlighted that the prevalence of obesity among men increased significantly between 1999 and 2000 (27.5\%) and between 2003 and 2004 (31.1\%). Among women, there was no significant increase during these periods ( $33.4 \%$ and $33.2 \%$, respectively), nevertheless, the values were still high. The prevalence of morbid obesity between 2003 and 2004 was $2.8 \%$ and $6.9 \%$ for men and women, respectively.

In a study by Gutiérrez-Fisac et al. [4] regarding the prevalence of overweight and obesity among the elderly in Spain, approximately $49 \%$ of men and $39.8 \%$ of women were overweight, and $31.5 \%$ and $40.8 \%$ were obese. This study also highlighted that the prevalence decreased with advanced age in both sexes. Among elderly men aged 60-69 years old, the values were higher (35\%) than in older 
subjects aged $\geq 80$ years old $(19.4 \%)$, and among older women the values also decreased from $43.8 \%$ to $29.2 \%$ when comparing the age ranges (60-69 and $\geq 80$ years old).

Fakhouri et al. [5], conducted a survey on the prevalence of obesity among the elderly in the United States. This study emphasized that for the elderly aged 65 years or older, the prevalence of obesity was approximately 35\% between 2007 and 2010, with no significant difference between the sexes, but with significant differences between ages. The elderly aged 75 years or older had a lower prevalence of obesity when compared with older individuals aged 65 to 74 years (27.8\% and $40.8 \%$, respectively).

In clinical practice, overweight and obesity are often determined by the values of the body mass index (BMI). For most cases this instrument can classify the individuals adequately [6], in addition to being a practical and accessible method. Several studies have shown a positive correlation between BMI and mortality; showing that BMI values, either above or below the normal values, are associated with an increased risk of premature death [7].

Overweight and obesity have a strong association with chronic disorders such as diabetes, cardiovascular diseases, and cancer [8-13]. The prevalence of adults with type 2 diabetes has increased in recent decades, coinciding with the rise in obesity epidemics [8]. Mokdad et al. [2], found a higher incidence of diabetes, high blood pressure levels, and high cholesterol levels in individuals with overweight and obesity than in the population with a body weight within the range understood as healthy.

This combination results in a financial burden on the healthcare system that can be relieved by public policies that make it possible to identify, classify, and enable public access to the interventions that can contribute to the control of and/or reduction in body weight. Thus, determining the incidence of overweight and obesity in each population is important for the development of public health policies. Moreover, understanding the prevalence of excessive body weight in specific regions might be important in order to understand the scenario and also to provide data for further comparisons, allowing insight into differences and similarities among different contexts.

Therefore, the aim of the present study is to determine the prevalence of overweight and obesity in volunteers at the primary healthcare center in the city of Goiania, Brazil.

\section{Materials and Methods}

The prevalence of overweight and obesity was calculated using data from a public primary healthcare center in the city of Goiania, Brazil, which serves approximately 10,000 individuals from the peripheral population. These healthcare centers are a part of a strategy of the Brazilian Health Single System, called SUS (Sistema Único de Saúde, Goiânia, Brazil). These centers serve the nearby population, in this case the peripheral population of the east region of Goiania City.

Data were collected between September and October in 2011 from the latest medical records of individuals aged 20 years or older. The exclusion criteria included being less 18 years old and having chronic diseases that could impact BMI (like cancer, AIDS, etc.). A total of 802 medical records from the healthcare center were eligible for participation in the present study who were followed by a Family Health Strategy team involved with 3000 to 4000 patients. After an initial data analysis of the patients' records, 13 were excluded from further analysis due to missing data. The data used in the present study included the age, weight, and height of 789 patients: 546 women $(43.9 \pm 16.4$ years, $66.2 \pm 13.3 \mathrm{~kg}$, $1.6 \pm 0.1 \mathrm{~m})$ and 243 men $(46.0 \pm 17.2$ years, $73.7 \pm 14.7 \mathrm{~kg}, 1.7 \pm 0.1 \mathrm{~m})$ who were registered with the Family Health Strategy team's physician. The volunteers gave consent for the use of the data and the manager of the healthcare center authorized the use of the data for scientific purposes. The study was approved by the Human Research Ethics Committee of the Federal University of Goias (CEP/CAAE: 64091717.0.0000.5083, 9 March 20117). All procedures were in accordance with recommendations from the Declaration of Helsinki.

Weight and height were measured using a balance scale and stadiometer (Filizola PL200, São Paulo, Brazil) with accuracy of $100 \mathrm{~g}$ and $0.1 \mathrm{~cm}$, respectively. Body mass index (BMI) was calculated by 
dividing the weight in kilograms by the square of the height in meters and was rounded to the nearest tenth of the last recorded weight. Overweight was defined when the body mass index was between 25.0 and $29.9 \mathrm{~kg} / \mathrm{m}^{2}$, and obesity at $30.0 \mathrm{~kg} / \mathrm{m}^{2}$ or higher [14]. The participants of each gender (women, w; men, $\mathrm{m}$ ) were stratified into five age categories: $20-29$ ( $20 \leq$ age $\leq 29$ years), 30-39 (30 $\leq$ age $\leq 39$ years), 40-49 ( $40 \leq$ age $\leq 49$ years), $50-59$ ( $50 \leq$ age $\leq 59$ years), and elderly (age $\geq 60$ years).

The Kolmogorov-Smirnov test showed that the data were not normally distributed. For each group, the median and interquartile range of the BMI are presented (Table 1). To compare the BMI among age groups and between genders, the Ranking Transformation type RT-1 [15] was performed on all data and an unbalanced two-way analysis of variance (ANOVA) was applied to the ranks. For comparisons in which the null hypothesis (the groups' medians were not different) was rejected, the Tukey-Kramer multiple comparison procedure was applied. Pearson's linear correlation test was used to check whether there was a linear relationship between BMI and age in each gender. The prevalence of overweight or obesity (BMI $\geq 25 \mathrm{~kg} / \mathrm{m}^{2}$ ) and obesity (BMI $\geq 30 \mathrm{~kg} / \mathrm{m}^{2}$ ) in each gender and age group are presented as bar graphs (Figure 1). The significance level was set at $5 \%$, and data analyses were performed using Matlab ${ }^{\circledR}$ (The MathWorks, Natick, MA, USA).

Table 1. Body mass index $\left(\mathrm{kg} / \mathrm{m}^{2}\right)$ of patients of the public primary healthcare center in the city of Goiania, Brazil.

\begin{tabular}{ccccccccccc}
\hline Variables & \multicolumn{1}{c}{ Women } \\
\hline Age Group & $20-29$ & $30-39$ & $40-49$ & $50-59$ & Elderly & $20-29$ & $30-39$ & $40-49$ & $50-59$ & Elderly \\
Median & $24.2^{*}$ & $25.5^{* *}$ & 26.3 & 27.6 & 28.0 & $22.0 * * *$ & 25.6 & 27.5 & 26.7 & 26.5 \\
IQR & 6.5 & 6.7 & 7.2 & 8.1 & 6.1 & 5.0 & 5.4 & 6.1 & 4.7 & 4.9 \\
\hline
\end{tabular}

IQR-Interquartile range; * lower than women older than 39 years; ${ }^{* *}$ lower than women older than 49 years; ${ }^{* * *}$ lower than men older than 29 years.
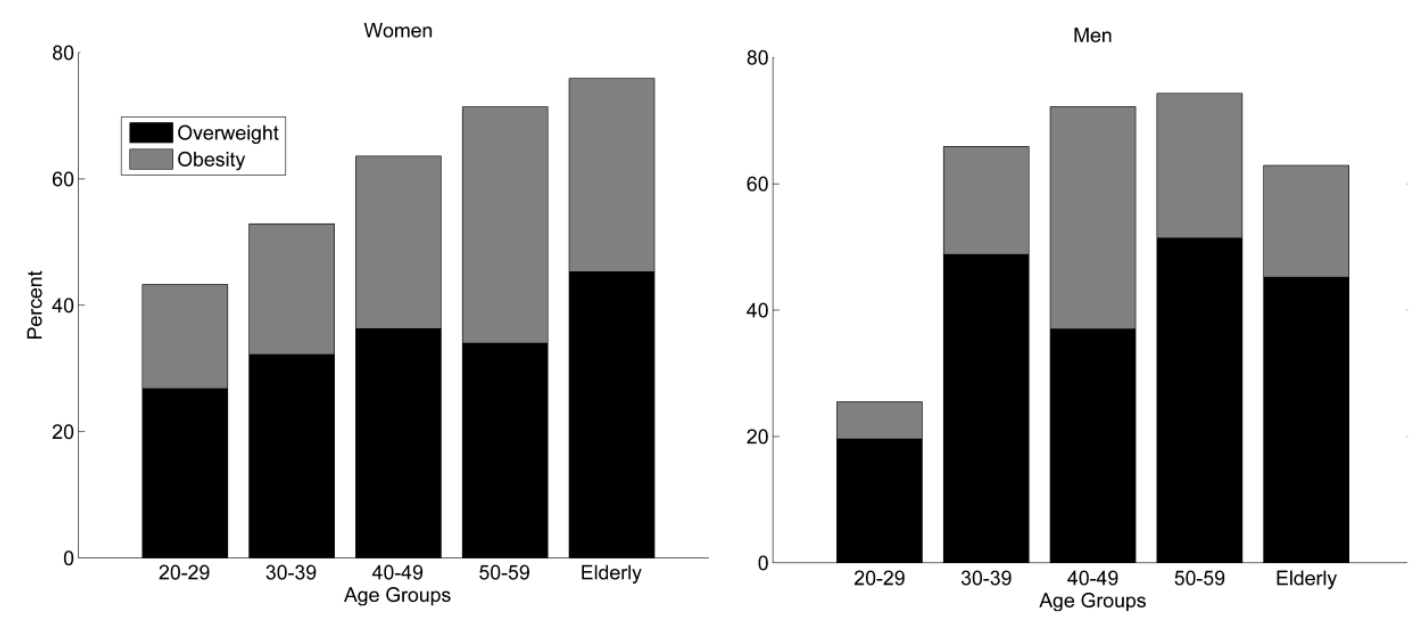

Figure 1. The prevalence of overweight and obesity in women (left) and men (right), who were patients of a primary healthcare center in the city of Goiania, Brazil.

\section{Results}

The variance analysis indicated no significant difference between genders for BMI $(p=0.0763)$; however, a significant difference among age groups was verified $(p=0.0000)$ since there was an association between gender and age $(p=0.0196)$. For both genders, the BMI increased with age (Table 1). The median BMI was within the overweight range for every group, except for the youngest. The BMI of women showed a linear relationship with age according to Pearson's test $(R=0.9811$; $p=0.0031)$, whereas that of men $\operatorname{did} \operatorname{not}(R=0.7084 ; p=0.1805)$. Similar to women, the men's BMI 
was lower for the youngest group (20-29), however, it abruptly increased at ages 20-29 and 30-39 and remained stable in the other age groups.

Among the groups analyzed, $36.1 \%$ were only overweight and $23.8 \%$ were obese, resulting in a total of $59.9 \%$ classified as overweight or obese. The percentage of overweight and obesity was above $50 \%$ in the population studied, with the exception of young men: $25.5 \%$ (overweight and obesity) and $5.9 \%$ (obesity) (Figure 1). Greater than $50 \%$ of the population over 29 years old was overweight or obese. The highest overweight prevalence was found in elderly women $(75.9 \%)$ and men aged 50 to 59 years $(74.3 \%)$. The highest obesity prevalence was found in women aged 50 to 59 years old $(37.4 \%)$ and men aged 40 to 49 years old $(35.2 \%)$, as demonstrated in Table 2.

Table 2. Overweight and obesity prevalence (\%) of patients of the public primary healthcare center in the city of Goiania, Brazil.

\begin{tabular}{ccccccccccc}
\hline Variables & \multicolumn{3}{c}{ Women } & \multicolumn{3}{c}{ Men } \\
\hline Age Group & $20-29$ & $30-39$ & $40-49$ & $50-59$ & Elderly & $20-29$ & $30-39$ & $40-49$ & $50-59$ & Elderly \\
Overweight & 26.8 & 32.2 & 36.3 & 34.0 & 45.3 & 19.6 & 48.8 & 37.0 & 51.4 & 45.2 \\
Obesity & 16.5 & 20.7 & 27.3 & 37.4 & 30.6 & 5.9 & 17.1 & 35.2 & 22.9 & 17.7 \\
\hline
\end{tabular}

\section{Discussion}

The aim of the present study was to analyze the prevalence of overweight and obesity in volunteers from a primary healthcare center in the city of Goiania, Brazil. For both genders, the central tendencies of the five age groups were analyzed (Table 1), and the prevalence of overweight or obesity $\left(\mathrm{BMI} \geq 25 \mathrm{~kg} / \mathrm{m}^{2}\right.$ ) and obesity (BMI $\geq 30 \mathrm{~kg} / \mathrm{m}^{2}$ ) were presented (Figure 1$)$.

According to data generated by Vigitel [16] in Brazil, $54.7 \%$ of men and $47.4 \%$ of women were overweight, and the values for obesity were $17.5 \%$ for both genders. In Goiania City, the values for overweight and obesity in both genders are approximately $48 \%$ and $16 \%$, respectively, which is in good agreement.

Other studies have evaluated the level of overweight and obesity in the population of Goiania City. Peixoto et al. [17], found an obesity value of over $70 \%$ in the elderly population of Goiania city, which is larger than that found in the present research. Carnelosso et al. [18], studied the same population and found $44.1 \%$ of overweight and obesity. Thus, the present study estimates an overall increase in this health problem, demonstrating the requirement for governmental action.

Silva et al. [19], performed a population-based study throughout the Brazilian territory (North, Northeast, Southeast, South, and Midwest) involving 81,745 adults of both genders aged between 20 and 59 years old. The prevalence of overweight and obesity in men was $30.4 \%$ and $8.1 \%$, respectively; and among women, the prevalence was $25.3 \%$ and $11.5 \%$ for overweight and obesity, respectively. In the Midwestern region of the country, the prevalence of overweight was $29.5 \%$ and obesity $9.7 \%$, while the present study found $36.1 \%$ of adults were overweight and $23.8 \%$ were obese.

The trend of an increasing prevalence of overweight and obesity in the population has been reported over the years [20]. This fact appears to be restricted to certain socioeconomic levels, as can be seen in the study by Monteiro and Conde [20], in which a secular trend of obesity according to social strata was reported following a comparison between the Northeast and Southeast of Brazil. Between 1975 and 1989, the development of obesity increased evenly in the two regions. During the period between 1989 and 1997, there was an increase in obesity in men in both regions, which was most significant in the Northeast. For women, this increase was more pronounced for intermediateand high-income strata. In the Southeast region, there was a decline for intermediate and high-income levels, and a significant increase for the low-income strata. The data in the present study were collected from a low-income region and the results confirm the same upward trend.

Flegal et al. [21], analyzed the prevalence of adult obesity from 2009 to 2010 using the National Health and Nutrition Examination Survey (NHANES). The results showed that the prevalence of 
obesity was $35.5 \%$ among adult men and $35.8 \%$ among adult women. The average value of obesity prevalence in our study was $15 \%$ for both sexes, however, for women aged between 50 and 59 years and men aged between 40 and 49 years, the results were $37.4 \%$ and $35.2 \%$ respectively, which correlates with the findings of Flegal et al. [21].

Among elderly women, the prevalence of overweight and obesity was $75.9 \%$, and among elderly men the prevalence was $62.9 \%$. The present results follow the trend of other studies, as can be seen from Gutiérrez-Fisac et al. [4], in which $80.5 \%$ of men and $80.6 \%$ of women were found to be either overweight or obese. Fakhouri et al. [5], showed that during the periods of 1999-2002, 2003-2006, and 2007-2010, there was a linear increase in the prevalence of obesity among elderly men. A comparison between 1999-2000 and 2007-2010 showed that the values increased by approximately $10 \%$ and $8.8 \%$ for elderly men (65-74 and 75 years or older, respectively). For women, the results were not statistically significant over the same period or between groups.

There exists scientific evidence associating weight gain and obesity with an increased risk of developing other diseases such as diabetes [2,22-24] cancer [10,11,13,22,23], metabolic syndrome, coronary heart disease, and hypertension [8,22-24]. Moreover, there is strong evidence of the importance of physical activity in reducing weight and maintaining a healthy weight after weight loss, as well as the benefits of an active lifestyle for health and a good quality of life [7].

The present study has important limitations related to the lack of information regarding the level of physical activity, socioeconomic level, and education of the population evaluated. This information could contribute to the deepening of knowledge and reflection of the problem and provide parameters for the creation of public policies. However, the data obtained may help to define health policies for the community studied, and allow comparisons with other populations.

\section{Conclusions}

The present results show a high prevalence of overweight and obesity among adults and the elderly, and a significant difference among age groups was verified with BMI increasing with age. These findings make it possible to create effective public policies that can contribute to the control of obesity and reduce the financial impact of these disturbances in public sectors, enabling accessibility and better living conditions for this population.

Author Contributions: E.C.G.P. and T.J.R.B. study design and data acquisition; C.A.V., P.G., M.H.B., W.D.N.d.S., G.d.C.T.C., C.A.B.d.L., E.C.G.P. and T.J.R.B. data analysis, manuscript drafting and revision

Conflicts of Interest: The authors declare no conflicts of interest.

\section{References}

1. Linhares, R.S.; Horta, B.L.; Gigante, D.P.; Dias-da-Costa, J.S.; Olinto, M.T.A. Distribution of General and Abdominal Obesity in Adults in a City in Southern Brazil. Cadernos de Saude Publica 2012, 28, 438-447. [CrossRef]

2. Mokdad, A.H.; Ford, E.S.; Bowman, B.A.; Dietz, W.H.; Vinicor, F.; Bales, V.S.; Marks, J.S. Prevalence of Obesity, Diabetes, and Obesity-Related Health Risk Factors, 2001. JAMA 2003, 289, 76-79. [CrossRef] [PubMed]

3. Ogden, C.L.; Carroll, M.D.; Curtin, L.R.; McDowell, M.A.; Tabak, C.J.; Flegal, K.M. Prevalence of Overweight and Obesity in the United States, 1999-2004. JAMA 2006, 295, 1549. [CrossRef] [PubMed]

4. Gutiérrez-Fisac, J.L.; López, E.; Banegas, J.R.; Graciani, A.; Rodríguez-Artalejo, F. Prevalence of Overweight and Obesity in Elderly People in Spain. Obesity 2004, 12, 710-715. [CrossRef] [PubMed]

5. Fakhouri, T.H.I.; Ogden, C.L.; Carroll, M.D.; Kit, B.K.; Flegal, K.M. Prevalence of Obesity among Older Adults in the United States, 2007-2010; National Center for Health Statistics: Hyattsville, MD, USA, 2012.

6. Pedersen, B.K.; Saltin, B. Evidence for Prescribing Exercise as Therapy in Chronic Disease. Scand. J. Med. Sci. Sports 2006, 16, 3-63. [CrossRef] [PubMed]

7. Pedersen, B.K.; Saltin, B. Exercise as Medicine-Evidence for Prescribing Exercise as Therapy in 26 Different Chronic Diseases. Scand. J. Med. Sci. Sports 2015, 25, 1-72. [CrossRef] [PubMed] 
8. Ard, J. Obesity in the US: What Is the Best Role for Primary Care? Br. Med. J. 2015, 350, g7846. [CrossRef] [PubMed]

9. Esposito, K.; Pontillo, A.; Di Palo, C.; Giugliano, G.; Masella, M.; Marfella, R.; Giugliano, D. Effect of Weight Loss and Lifestyle Changes on Vascular Inflammatory Markers in Obese Women. JAMA 2003, 289, 1799. [CrossRef] [PubMed]

10. Carmichael, A. Review Article: Obesity as a Risk Factor for Development and Poor Prognosis of Breast Cancer. Int. J. Obstet. Gynaecol. 2006, 113, 1160-1166. [CrossRef] [PubMed]

11. Renehan, A.G.; Tyson, M.; Egger, M.; Heller, R.F.; Zwahlen, M. Body-Mass Index and Incidence of Cancer: A Systematic Review and Meta-Analysis of Prospective Observational Studies. Lancet 2008, 371, 569-578. [CrossRef]

12. La Vecchia, C.; Negri, E.; Franceschi, S.; Talamini, R.; Bruzzi, P.; Palli, D.; Decarli, A. Body Mass Index and Post-Menopausal Breast Cancer: An Age-Specific Analysis. Br. J. Cancer 1997, 75, 441-444. [CrossRef] [PubMed]

13. Kushi, L.H.; Doyle, C.; McCullough, M.; Rock, C.L.; Demark-Wahnefried, W.; Bandera, E.V.; Gapstur, S.; Patel, A.V.; Andrews, K.; Gansler, T.; et al. American Cancer Society Guidelines on Nutrition and Physical Activity for Cancer Prevention. Cancer J. Clin. 2012, 62, 30-67. [CrossRef] [PubMed]

14. World Health Organization. Obesity: Preventing and Managing the Global Epidemic. Report of a WHO Consultation; World Health Organization: Geneva, Switzerland, 2000.

15. Conover, W.J.; Iman, R.L. Rank Transformations as a Bridge Between Parametric and Nonparametric Statistics. Am. Stat. 1981, 35, 124-129.

16. Vigitel. Vigitel Avaliação; Ministério da Saúde: Brasília, Brazil, 2013.

17. Ferreira, C.C.; Peixoto, M.R.G.; Barbosa, M.A.; Silveira, É.A. Prevalence of Cardiovascular Risk Factors in Elderly Individuals Treated in the Brazilian Public Health System in Goiânia. Arq. Bras. Cardiol. 2010, 95, 621-628. [CrossRef]

18. Barbosa, M.A.; Carnelosso, M.L.; Porto, C.C.; Silva, S.A.; Carvalho, M.M.; Oliveira, A.L.I. Prevalence of Risk Factors for Cardiovascular Diseases in the East Region of Goiânia, Goiás State. Cienc. Saude Colet. 2010, 15 (Suppl. 1), 1073-1080.

19. Silva, V.S.; Petroski, E.L.; Souza, G.I.; Silva, D.A.S. Prevalence and Factors Associated with Overweight Adults in Brazil: A Study of Population-Based throughout the National Territory. Revista Brasileira de Ciências do Esporte 2012, 34, 713-726. [CrossRef]

20. Monteiro, C.A.; Conde, W.L. A Tendência Secular Da Obesidade Segundo Estratos Sociais: Nordeste E Sudeste Do Brasil, 1975-1989-1997. Arq. Bras. Endocrinol. Metabol. 1999, 43, 186-194. [CrossRef]

21. Flegal, K.M.; Carroll, M.D.; Kit, B.K.; Ogden, C.L. Among US Adults, 1999-2010. Am. Med. Assoc. 2012, 307, 491-497. [CrossRef] [PubMed]

22. Ogden, C.L.; Carroll, M.D.; Flegal, K.M. Epidemiologic Trends in Overweight and Obesity. Endocrinol. Metab. Clin. N. Am. 2003, 32, 741-760. [CrossRef]

23. Ogden, C.L.; Yanovski, S.Z.; Carroll, M.D.; Flegal, K.M. The Epidemiology of Obesity. Gastroenterology 2007, 132, 2087-2102. [CrossRef] [PubMed]

24. Kumanyika, S.K.; Obarzanek, E.; Stettler, N.; Bell, R.; Field, A.E.; Fortmann, S.P.; Franklin, B.A.; Gillman, M.W.; Lewis, C.E.; Poston, W.C.; et al. Population-Based Prevention of Obesity: The Need for Comprehensive Promotion of Healthful Eating, Physical Activity, and Energy Balance: A Scientific Statement from American Heart Association Council on Epidemiology and Prevention, Interdisciplinary Commi. Circulation 2008, 118, 428-464. [CrossRef] [PubMed]

(C) 2018 by the authors. Licensee MDPI, Basel, Switzerland. This article is an open access article distributed under the terms and conditions of the Creative Commons Attribution (CC BY) license (http:/ / creativecommons.org/licenses/by/4.0/). 